

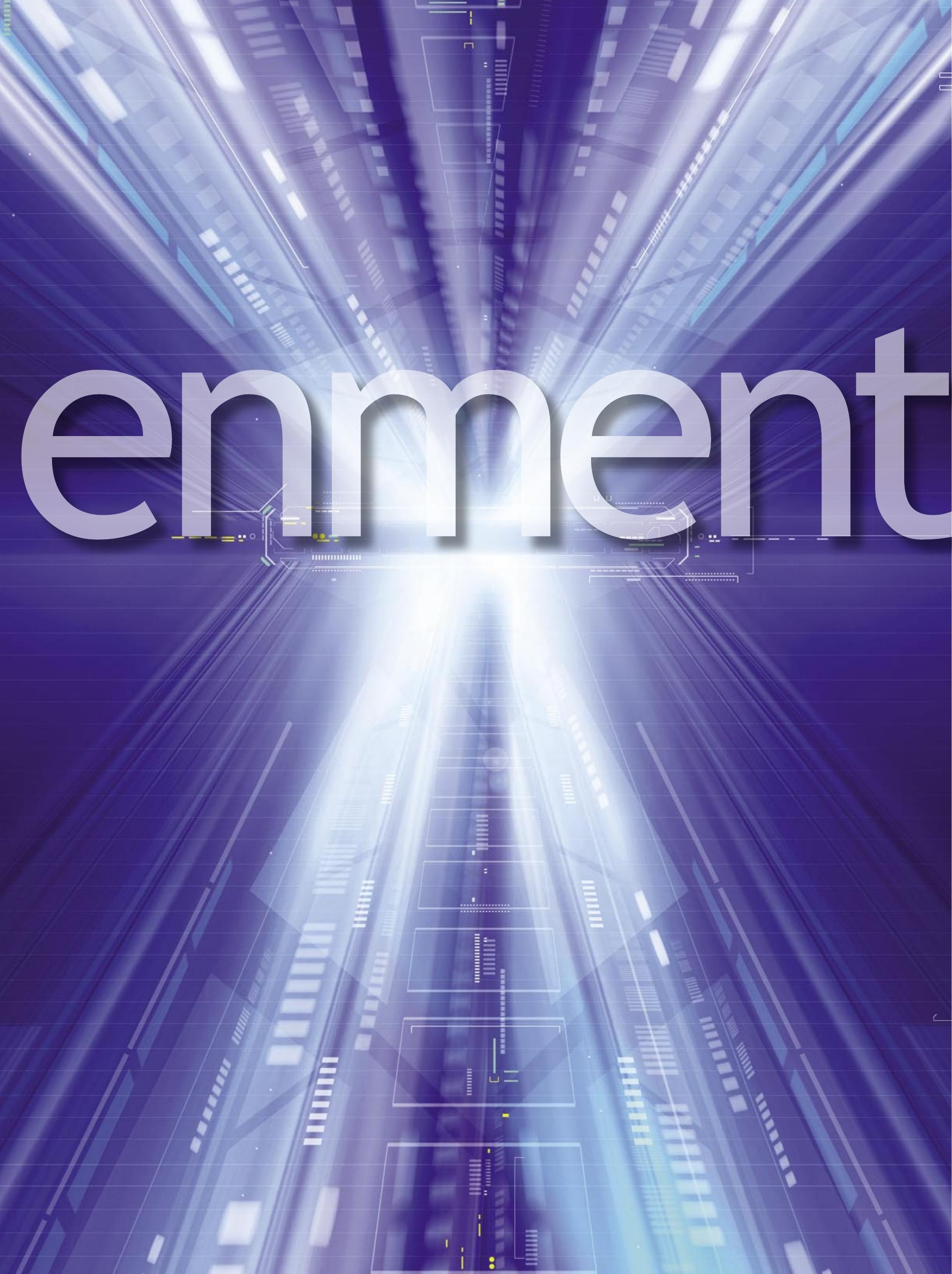




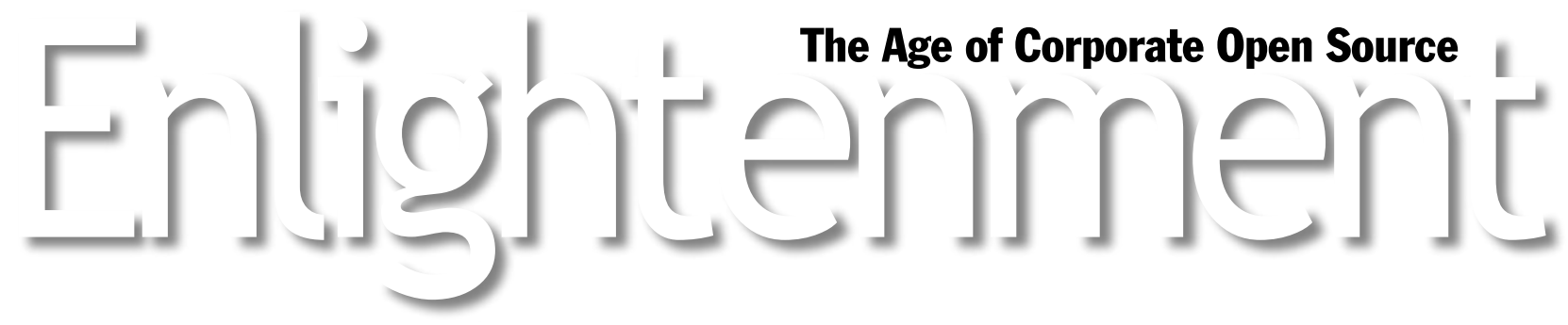

The constant blur of change in IT doesn't help matters much either.

Consider this a feeble attempt to explain some of the undercurrents in the open source movement as they pertain to corporate America today. Sure, it would be nice to avoid the religious metaphor, but doing so would leave out some of the most important elements driving this change, along with the caveats that are a part of the craziness of it all.

Until recently, open source software has been an enigma to many in corporate America. Faced at first with mystery, then disbelief, then emergence, then hype, and finally exposure, corporate America has now had enough and is bowing to the inevitable. It is embracing open source software. Gone are the dire predictions of nonexistence, inferred commu-

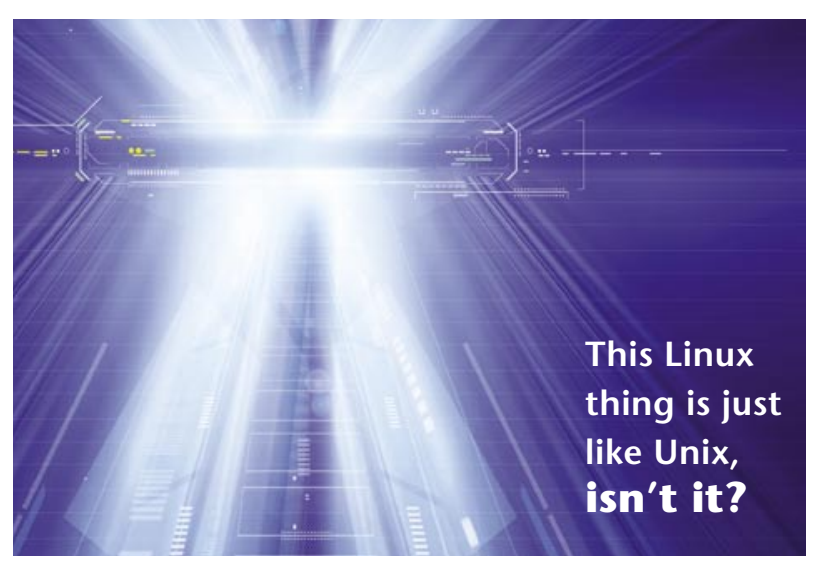
nism, insecurity, and Lord knows what else-impotence, perhaps?

In its place is something rather unexciting: acceptance, approval, and-dare I say-boring old cost savings and commonsense practicality. Open source software, once the tool of the fanatic, is now the standard embraced by those at the top tier of corporations throughout America. It has illuminated the path to cost savings and expansion in uncertain times when budgets are shrinking. It has become a method to improve the power-to-weight ratio of the IT staff.

It wasn't always like this.

The corporate IT past is riddled with holy wars. The client/server-versus-mainframe war is but one example. The open source war is different. Any time you introduce a ground-up concept (say, one about free software) into a top-down culture (say, for-profit corporate America), you're going to have bloodshed. This article will examine the "religious" aspects of the situation, mostly from the perspective of two hypothetically extreme players-the zealots and the heretics.

\section{THE ZEALOTS}

The zealots are open source fanatics. Microsoft might make their lives easier, but zealots cannot stand the thought of that software on their hardware. It runs against their fundamental belief system. If you're an IT executive in corporate America today, you might be thinking something like, "Darn good thing I don't have any of those zealots working for me."

If that's the case, you can forget about it: There are open source zealots in any sizable IT organization. If the environment is such that open source software is frowned upon-guess what?-the zealots have gone underground. They're not sharing their beliefs publicly. They have quietly been using Linux at home to make firewalls, file servers, networks, and God knows what else-all in the name of practicing their religion and creating a little joy in their constrained geeky existence. They're likely helping out the local Linux users group on top of it all. Asked where they work, they may become evasive.

Breeding more control at work and stifling choices doesn't make people automatically stop thinking about the forbidden fruit. It just makes them go home as early as possible so the fun can really begin.

You may even (Heaven forbid) already have open source software in multiple forms on your network-it's actually more likely than not. You see, the zealots have a way of making friends and hiding the religious artifacts of their trade. Many a story among the converted revolves around pointy-haired bosses bragging about proprietary servers that are really masquerading Linux or Berkeley Software Distribution (BSD) boxes. Bonus points 
are awarded for statements about how some open source product is a rejected standard, while the snickering zealots know that the solution has been ticking away quietly for years, right under the guy's nose.

You may be thinking that all of this talk of religion is directed only one way-from the zealots as I've described them. But that's simply not the case. It goes both ways.

\section{Note to the IT Executive}

If your organization hasn't switched in some areas to open source solutions, the zealots are increasingly restless. They're tired of seeing the corporate budget dedicated to purchases of "solutions" that have open source counterparts. Often, these counterparts have grown more fullfeatured, stable, and secure than their costly alternatives. If the heretics are running the show, more fuel is added to the fire.

Pre-open-source corporate America had its religion too. For all intents and purposes, open source concepts-at least on the misunderstood surface-go against the commonly held belief of a lot of old-school managers. After all, at first glance, and even possibly at second glance, the concepts of business model and intellectual property rights seem to be at complete odds. If I had to identify the biggest leap of faith of all of the possible leaps out of the open source conundrum, I'd have to say that it's the answer to, "How does anyone make money selling this?"

The implications are very stark: "This isn't going to survive in the long run," "This doesn't come with support," and "This is something for nothing; therefore, it doesn't exist."

Forgetting Red Hat in this equation, the real question is: "Can a product exist without a profit-centered owner?"

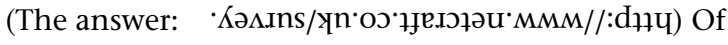
course it can. Apache powers a whopping 60-plus percent of the Web. It's been that way for a long, long time now. Claiming it doesn't exist would be heresy.

This brings us to the other major open source player.

\section{THE HERETICS}

The heretics are found at the other extreme of the religious spectrum. They're just as fanatical about their beliefs, and for many reasons don't want to believe in open source software as a corporate solution. They're just as likely as zealots to defend their points of view at great length. This isn't meant to imply that these people are in any way stupid. They just suffer from the same problem as the zealots-mixing religion and politics.

It should be noted that heretics are a dying breed. There are multiple reasons for this, not the least of which is conversion, but it's not quite that simple. Every day heretics are being confronted with more and more proof that in the past was extremely easy to overlook.

This proof comes in many forms. For example, Linux was an easy thing to dismiss when it was just a bunch of crazy people on the Web. ("Those people were high/ crazy/stupid communists.") It was easy to dismiss when the IPOs came and went. ("It's just like the dot-coms! This is a flash in the pan!") And it was easy to dismiss when some of the people came in talking about running it on their home PCs. ("I can do all of that with Windows/ Solaris/AIX Server.")

What's now making it difficult to dismiss are the nontechnical people in the corporation who are running around demonstrating Open Office's presentation capabilities, or worse, the CIOs who decree that Linux is now the corporate standard for some core business function.

Suddenly the proof is part of daily existence. The dynamics of this situation are, of course, ugly. Some serious burning at the stake may be the order until things settle down.

\section{HOLYWAR IN THE AGE OF}

\section{OPEN SOURCE ENLIGHTENMENT}

For the most part, the zealots have been rather patient. In the most stifling environments they have resigned

\section{Scanning for Vaporware}

During a software inventory at a large corporation, one of the heretics on the network where a zealot friend of mine worked discovered what appeared to be an illegal (nonapproved) operating system: Windows 2004 Advanced Server. The zealot was approached about the matter. It seems that his joke of using the Samba server identifier string was not appreciated. After much deliberation, high council deemed that his desktop did not, in fact, have Windows 2004 Advanced Server (darn good thing, given the fact no such product existed, even as alpha code, at the time).

Open source zealots and heretics have to find common ground. Situations like that just described shake the firmament of the heretics. They make life entertaining for the zealots, but they don't make any friends. Zealots beware: A little bit of diplomacy can go a long way toward speeding the introduction of things that add joy to your life. 


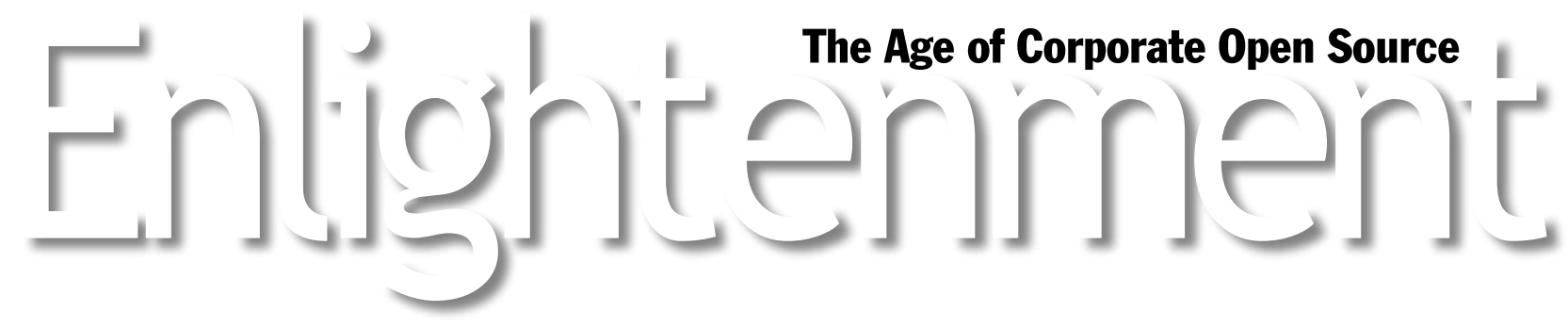

\section{Executives Discovering The New World}

An IT zealot friend related the following experience to me:

A customer wanted us to make our product less expensive. The customer asked, "What about the 'L' word?'

Silence-no one said a thing, but simply turned their heads toward me because I've been hyping Linux for years.

The customer went on to say that we would be foolish not to at least look at standardizing on Linux-front-end, back-end, everything.

Realistically, I knew converting everything to Linux would probably never happen, but even if we could reduce the cost of the product by 5 or 10 percent, the savings for the customer would be significant.

There's definitely a buzz from the business folks. For some reason it started about six months ago. I don't know why. But when they come to us, it's like they're Columbus discovering the "New World," only we "Indians" have been here for years.

themselves to the idea that they're going to use Linux at home and Unix or some other proprietary solution at work. The pressures to continue using open source software have been brought on by an increasing sense of frustration with proprietary solutions.

In these situations, the appearance of an unexpected ally can be a total surprise to the zealots. This ally is often a corporate purchasing agent, but not always. The stories range from people in marketing running about with bootable Linux CDs to the CEO asking pointed questions that only have open source answers.

One of my friends recently experienced such a change at his workplace. "I never thought I'd see the day when the corporation would adopt as a standard something that just a few short months ago I was being taunted about," he said. Management was suddenly seeing the open source light, so to speak. Nonetheless, something about this bothered my friend: the feeling that management hadn't been listening to him-not in the past, and possibly not even now. Sigh.

The zealots have to realize that these decisions aren't religious in nature. The CEO isn't making the call from the point of view of a belief system. The zealots may have chosen open source solutions because they're fun, creative, empowering, and cool; the executive decisions are likely being made for economic, strategic, and practical reasons. The zealots must also realize that these unholy alliances may be only temporary. Nothing is permanent, especially in the fast-changing world of IT.

\section{DESKTOP ARMAGEDDON}

The final battle has many fronts. The one most people focus on has been the battle for the corporate desktop. While important, it's shaping up to be rather insignificant in terms of core business functionality. Open source software isn't necessarily breaking speed barriers in this department, but it's making incredible inroads replacing proprietary Unix on the back end. It's being pushed by SAP and Oracle and being leveraged by survivors of the New Economy-eBay, Yahoo, Amazon, and Google, to name a few.

This suits the zealots-most of them aren't desktopfocused individuals; they're hard-core developers, systems administrators, database administrators, and-most surprisingly-even old-school mainframe types.

As such, there seems to be confusion as to why the open source revolution hasn't occurred on the desktop.

Linux, for example, doesn't fit everywhere. It's great on servers and great for doing Web development and other kinds of automation or application development, but it has been a hard sell as a Windows replacement on the desktop. This is likely because it's such a bad fit there. This problem stems from the root of origin of both products.

Microsoft Windows and the software that runs on it grew out of a desktop-centric view, out of a company that still contains an indicator of its specialty in its name: Micro(computer)Soft. It's a fundamental problem. As one of my friends is always saying, "I'm all about that!" Well, Microsoft is "all about" making (non-network) desktopcentric computer platforms. It still doesn't own the Web 
and likely will never own the server space on the Internet. The inertia is simply too great. A good argument can be made that it's all in the name-fundamentally; the company is focused on making great software applications for micros, not for network computers.

Its customers have grown up learning all about how Microsoft is going to make their desktop lives easier. Try this simple experiment. Stop a typical desktop user in the hallway and ask what .NET is going to do for that user. I've done it. No one knows. If you ask typical desktop users what Windows does for them, they're still kind of baffled, but usually they have some remote idea that it's

\section{A Zealot's Joke}

"I was installing some updates last night, and I was presented with a dialog box that had just one checkbox and the words, "I want to secure my system."

The zealot asked, "What did you do?"

Answered the heretic, "I selected the checkbox and said, 'OK.' Windows promptly shut off my computer."

Note: Heretics don't find this funny.

the thing that launches Solitaire for them.

Everything is seen and marketed through desktopcolored glasses. The paradigms by which Microsoft describes its products are extremely two-dimensional: a video monitor. Microsoft is "all about" ease of use-at all (or almost all) costs. Security and stability seem to have come last in the equation (these are nebulous items, difficult to describe in pretty icon-peppered pictures). Procurement cost is related to this functionality and technical support is implied, albeit most people don't rate Microsoft technical support high on their list of values.

In stark contrast, you have free software or open source software such as Linux and Apache. These items grew out of a network focus. Open source software names were practically chosen as an afterthought. It's not about marketing at all-that's also an afterthought. Cost? What's that? Ease of use? Not needed. Customer? The developer is the first customer. Users are chastised for not reading documentation if things don't work. The customer is responsible for support in some or all cases.

There are obvious exceptions to this very general description (support can often be purchased for open source software, for example). But these are important paradigms to remember when you're crossing religious boundaries. Say you're an open source zealot and you're talking to a heretic. The heretic's world view usually doesn't allow for successful solutions that are free. It goes against what's good for the company, the economy, and often the heretic's experience. Worse, heretics may have banked their careers on this belief. Now you're crossing into political areas.

Whether or not open source software belongs on the desktop at this time is somewhat debatable. There are

\section{Open Source Virus Protection}

A zealot friend had two desktops: a Linux box and a Windows box. Both were connected to the corporate LAN. The Windows box got infected during the Nimda worm attack a couple of years ago. The majority of the desktops in the corporation were infected in a matter of minutes. Unfortunately, it was taking weeks to reinstall windows on most of the PCs. This guy went to the PC department and procured the Windows 2000 CDs and did his own install. While waiting for the install to finish (his second install in as many months), he decided that to save time and infections in the future, he was going to change his network architecture: He used his Linux box as a firewall for the Windows box. He installed a second network card and used a pass-through cable to the Windows box to firewall off the hostile (corporate) LAN.

There was only one small problem: A heretic ran the PC department. The heretic's job was to make sure that all of the corporate PCs had the latest updates of anti-virus software on them, and my friend's firewall worked too well. The end result: The heretic could no longer even see the Windows box on the LAN, even though the Windows box was as functional as a desktop as it had been in the past, mounting network drives and so on.

This did not amuse the heretic whatsoever. The following conversation ensued:

Heretic: "You need to reconnect your desktop to the corporate LAN."

Zealot: "Why?"

Heretic: "I need to be able to push the latest virus definition files onto it."

Zealot: "It's not going to ever get a virus again. I've firewalled it off. I check my e-mail via pine on my Linux box."

Heretic: "What's pine?!?"

Zealot: "It's not elm..."

As you can imagine, a battle of wills began, the heretic eventually gaining the upper hand and succeeding in getting the Windows box connected. Heretics may appear clueless, but they're often well-connected politically. 


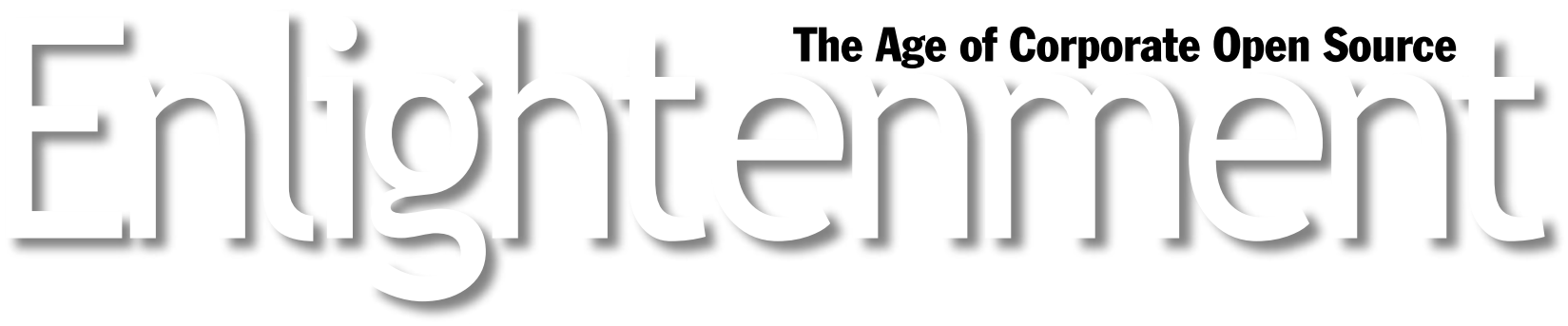

other areas where such value is extremely obvious. Security and stability are often primary concerns, followed closely by cost and manageability. Since $9 / 11$, security has moved up a notch or two on the value scale.

But do marketing and security belong together conceptually? For example, are proprietary vendors necessarily going to present the buyers of their technology with the truth-especially if it's an unpopular truth? The big lie is that somehow all computing situations, especially security-focused ones, can somehow be addressed with simple dialog boxes front-ending some vastly intelligent brain under the hood. Real security unfortunately requires real understanding, design, vigilance, and-sorry to say-expertise.

In short, anyone selling you some static, end-all solution that doesn't need some kind of perseverance is selling you a big lie, which is why the truth about security often doesn't go over well in business circles. On top of this, it doesn't help much when some of the most popular proprietary products have tons of security problems-especially when they represent the front door to a company, as a Web server often does.

Although the zealots aren't happy with the political climate, they do tend to be quite smug about the situation of proprietary insecurity in the corporate world. The heretics are quick to balance this by pointing at any flaw found in open source software and, quite correctly, sensing some overconfident arrogance.

Neither side should be happy. The truth, in this case, is a hard sell. Heretics and zealots alike have a big enough

\section{Microsoft Office- Linux Interoperability Experiment (MOXIE)}

HAL R. VARIAN, U.C. BERKELEY CHRISTOPHER M. VARIAN

A chief concern about moving to Linux is interoperability with Microsoft Office applications. Several office suites are available for Linux systems, but there hasn't been a systematic study of how well these suites interoperate with Microsoft Office. We decided to conduct a small pilot experiment to explore how interoperable current Linux office applications are with Microsoft Office.

On January 11, 2003, we downloaded 150 files from the Internet: 50 Word (.doc) files, 50 Excel (.xls) files, and 50 PowerPoint (.ppt) files. We used
Google's advanced search capability to restrict the files to these formats. Our search word, which is the 93rd most common word in the English language, was "first." We view this as a random selection of Microsoft Office files; there could be many other sampling methodologies.

During the week of January 21, we repeated this sampling process, this time using the word "blue."

We then attempted to load these files into four popular

\begin{tabular}{|c|c|c|c|c|c|c|}
\hline Suite & Program & Fine & Minor & Fixable & Unusable & Score \\
\hline StarOffice & Writer & 93 & 3 & 1 & 3 & 97 \\
\hline & Calc & 99 & 0 & 0 & 1 & 99 \\
\hline & Impress & 93 & 1 & 1 & 5 & 95 \\
\hline OpenOffice & Writer & 90 & 3 & 4 & 3 & 97 \\
\hline & Calc & 98 & 0 & 0 & 2 & 98 \\
\hline & Impress & 92 & 1 & 1 & 6 & 94 \\
\hline Gnome & Abiword & 72 & 11 & 10 & 7 & 93 \\
\hline & Gnumeric & 91 & 0 & 0 & 9 & 91 \\
\hline & Agnubis & $\mathrm{n} / \mathrm{a}$ & $\mathrm{n} / \mathrm{a}$ & $\mathrm{n} / \mathrm{a}$ & $\mathrm{n} / \mathrm{a}$ & $n / a$ \\
\hline KOffice & KWord & 74 & 8 & 6 & 12 & 88 \\
\hline & KSpread & 64 & 0 & 7 & 29 & 71 \\
\hline & KPresenter & $\mathrm{n} / \mathrm{a}$ & $\mathrm{n} / \mathrm{a}$ & $\mathrm{n} / \mathrm{a}$ & $\mathrm{n} / \mathrm{a}$ & $n / a$ \\
\hline
\end{tabular}


battle selling security policies to upper management. The truth about security is that it's a job that's never finished. The truth about security is extremely unmarketable. Much more marketable are concepts such as "Zero Administration" and "Trustworthy Computing."

It's not all black and white (or green, for that matter). A lot of businesses have caught on to these problems and aren't trusting their front doors (or even the safes in the virtual backrooms) to proprietary solutions with bad track records.

\section{OPEN SOURCE PRESSURES FACING CORPORATE IT TODAY}

From the zealots. Let's face it, more and more zealots are finding higher and higher places to roost on the corporate ladder. They're making life tough on corporate decision-makers and proprietary vendors alike. When you have capable people with a broad understanding of what they can do with open source software, they're not as likely as they may have been in the past to purchase products that are effectively old technology. Web, application, and file and print servers, for example, now fit this description.

Linux office suites: OpenOffice 1.0.1, StarOffice 6.0 (PP1), Gnome Office (consisting of Abiword 1.02 and Gnumeric 1.09), and KOffice (1.2 RC1). The operating system was Red Hat Linux 8.0.

We classified errors into three categories: minor, which were typically slight differences in appearance resulting from font substitution and the like; fixable, which generally involved a few minutes of adjustment; and unusable, which meant exactly that.

The results are summarized in Table 1.

StarOffice 6.0 is the winner of the compatibility sweepstakes, with only one to five unusable files in each category. OpenOffice, which is a fully open source application based on the StarOffice 5.2 code base, is a close second. Gnome Office and KOffice are distant contenders. They have much more immature presentation applications, with KPresenter unable to load any of the PowerPoint graphics. Agnubis was not tested because we couldn't find a working version.

In general, most errors had to do with table alignment, font substitutions, and graphics. Some of the problem files were from older versions of Microsoft Office applications, which the open source applications do not appear to support as well as more recent versions.

It is important to note that even Microsoft Office has trouble opening some versions of Microsoft Office programs,

\section{The truth}

about

security is

that it's a job

that's never

finished. The

truth about

security is

extremely

unmarketable.

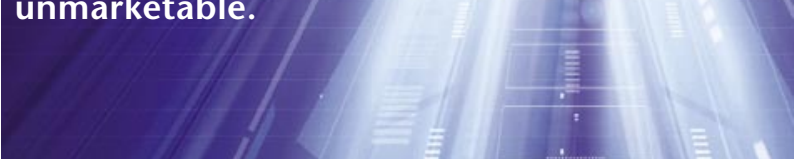

From the suits. Well-educated executives are agnostics. They don't care about "open source" or "proprietary" as concepts. All they know is that everyday they're reading about Amazon, Yahoo, Google, or some brick-andmortar company that's made the switch and saved a ton of money while gaining some seriously tangible benefits.

These people often have very little emotional capital in decisions already made and are not going to have

as forward compatibility has often been a problem. We used Office 2000, which succeeded in opening all Office files, but we venture to guess that Office 98 , say, would have had difficulties with some of them.

One could quarrel with our sampling methodology. Files posted on the Internet are often there to be read by others and may well be more generic than files distributed within a typical organization. Most of the Microsoft Word files that we downloaded, for example, did not use mathematics, outlines, tracking changes, or other such features.

This particular experiment should be considered a pilot study that could be extended to a larger one, and perhaps automated to some degree. Nevertheless, the results are suggestive: The current state of interoperability is reasonably good, although there is significant room for improvement.

HAL R. VARIAN is a professor of information management, economics, and business at the University of California at Berkeley. He works on the economics of information technology.

CHRISTOPHER M. VARIAN is 16 years old and does not yet have a biography, although he is looking forward to acquiring one.

Moxie image reprinted with permission of Monarch Beverage Company. 


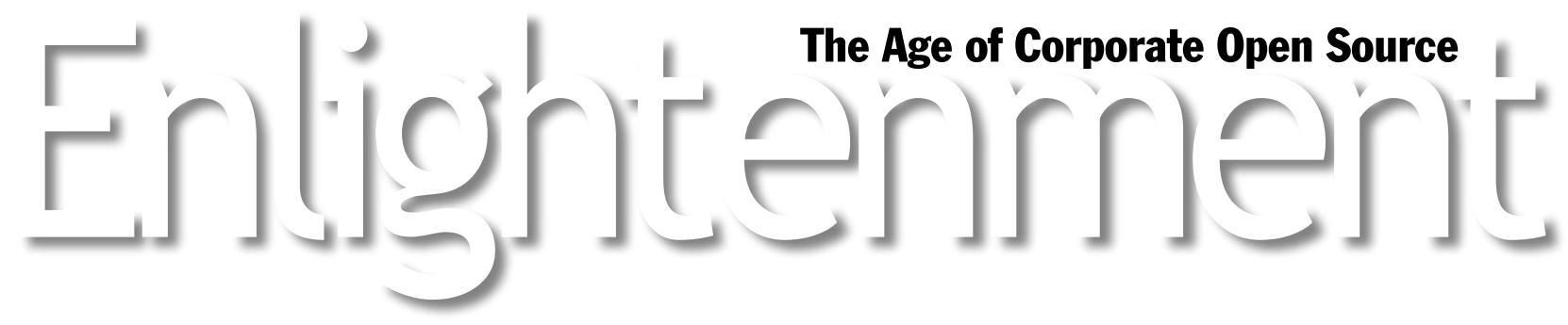

emotional spasms about selecting open source solutions. It's not going to bother them that some expensive database can be replaced by Postgres or MySQL; most likely, they didn't make the recommendation for the original system. What these people do know is that they need tangible results, today. They are less and less likely to care about legacy proprietary solutions.

From the economy. Let's face it, the bad economy has helped Linux and Apache. Proprietary vendors with fat profit margins and huge bank accounts that have attempted to raise pricing in this climate have not exactly made a lot of friends. In other words, CIOs and CFOs are not happy. The pressure to revisit the company's bad choices of the past is suddenly coming from the top. More than one of my zealot friends has reported the experience of an out-of-the-blue visit from a suit, several layers above, asking pointed questions about why the company isn't using more open source products.

On top of all of this, Microsoft has made it extremely clear that it's not going to lose any fight to Linux. As usual, the media has access to some really juicy internal sales memos on Microsoft's strategy. It's really amazing how much information leaks out of that company. Even more striking is how often the leaks provide valuable information that can help explain just what a tough competitor Microsoft is.

Regardless, a recent leak involved a "win-at-all-costs" strategy to keep large corporations in the fold. The memo in question made clear that, no matter what, in certain corporate settings a sale was not to be lost to Linux (see "MS 'Slush' Fund Provides Big Discounts to Stop LinuxE-mail," by John Lettice, The Register, May 15, 2003, http: //www.theregister.com/content/4/30715.html).

Oddly enough, this provides a really good reason for companies to adopt an open source strategy. For one, it isn't going to cost much to create an evaluation committee to, let's say, look at replacing all corporate desktops with Linux. Granted, it may not be a workable solution for the company; it may be totally unsupportable given the current desktop support staff, Windows inertia of expertise, applications, and so on.

Given the Microsoft sales strategy, however, the rules change. A sizable company with a large Microsoft desktop investment would be crazy not to create a credible internal initiative that evaluates open source.

With a credible internal initiative-and some leaked memos of your own to the local Microsoft sales rep-the purchasing agent for your company would likely see a huge benefit from a cost standpoint. Use this to your advantage: If you have a sizable Microsoft contract, do the open source software evaluation and make sure your Microsoft sales representative knows about it. The main point is that corporate America suddenly has one more reason to evaluate open source (even, God forbid, on the desktop), and it's a tactical one: leverage. (Who knows, you may even learn something in your evaluation that sheds new light on open source software and its appropriateness in your organization.)

From the security risk. The "Open Source Is More Secure" mantra isn't all that it's cracked up to be. The truth is that some topnotch open source solutions exist in the security department (such as OpenBSD), and some exploits and issues have come and gone that weren't much fun to brag about. Although it's great that the open source track record is generally good, and that a lot of mature projects such as Apache and Samba are relatively secure, as mentioned previously, security is an ongoing initiative-one that takes serious resources.

Implement any solution-including one based on open source software-in its default configuration and leave it exposed to a hostile environment for awhile. If it's providing services to that environment, there are going to be "issues."

Still, because open source has typically faced more scrutiny in the places that count (e.g., the front door and the vault), it fills the bill better than a lot of proprietary solutions when security is a concern (so say the zealots). It lacks buzzwords such as "trustworthy computing," but that's a vaporous apparition that still has not emerged as a workable solution to the corporate security ill.

From the ghost of Microsoft past. As if all of these pressures weren't enough, a serious revisit to the Microsoft marketing methods of the past will help clarify 
things a bit. In the past, Microsoft executives have often stated that their worst competition comes from their own installed base of customers. They have to come up with new ways to get corporate America to repurchase technology it already owns. This, unfortunately, has bred a lot of buzzword mania. Most people are now onto the game of the yearly smoke-fest, whereupon the latest buzzword is announced, some new pricing scheme is rolled out, and the same old pig with some new lipstick is hyped as the latest, greatest "solution" to your business problems, and it will be available next year-OK, maybe the year after that. For sure, it will be available before anyone else does it, and hopefully you will still need it by that time.

Yet, for some reason, the product delivered always seems to look like a new wrapper around some old Windows code.

This is no longer amusing. As one friend put it, "I'm tired of all of these acronyms being thrown at me. C\#, .NET, trustworthy computing, Microsoft BOB be damned-I just need a [expletive deleted] Web server. That's all! Just give me something that doesn't shut down every 24 hours and that's safe [and secure]."

You've got a company with $\$ 40$ billion or so in the bank and a need to continue the income rates it had previously. You've got a marketplace that's more or less in a state of IT depression. You've got a lot of businesses that have already purchased solutions and don't want to go through another round of upgrading to Lordknows-what new technology, especially for reasons that are contrived.

Plodding along, year after year, are open source solutions. There are few buzzwords. There is little marketing and no hype. In place of all that is something incredibly seductive to today's CIO_-boring, stable functionality that has steadily increased over the years without huge feature creep. Apache may have more capability today than it did five years ago, but what it mostly does (and does well) is serve Web content securely. That's what it promised to do for you five years ago. That's what it does today.

The message hasn't changed. How boring.

This, amazingly enough, has resulted in more pressure to use open source solutions. Corporate IT managers know that the proof is in the pudding. Commonly used open source solutions that were here years ago are still here today. If they had been hyped-up vaporous solutions, they would be gone.

\section{HEAVEN OR HELL?}

The points of view outlined in this article are extreme, but, unfortunately, the dynamics of the situation map well-more often than not. It's not all black and white, good and evil, saints and sinners. The reality is a spectrum, and the subject is still technology. Some applied level-headedness is in order. The best IT minds still know that nothing is absolute. There is no "best" solution to all IT problems, open source or proprietary. There are good fits and bad.

The bad dynamics always come into play when religion gets in the way of logical choice. Letting a heretic choose a bad proprietary solution for religious reasons is just as sinful as letting a zealot choose an open source solution when a proprietary one is better suited.

Not all zealots or heretics are exclusively driven by their emotions. In fact, most are not. A good argument can be made that the more obvious players are easier to manage. It's often the subtle choices that are made from hidden bias that cost the most dearly. The best solution comes about by bringing the choices out into the open and making them with an open mind.

Adoption of open source software still faces obstacles such as inertia, ignorance, and application availability, but these are shrinking. The recessive climate and growing list of successful adoptions are creating big opportunities for open source software. They give companies compelling reasons to switch paradigms, often realizing 


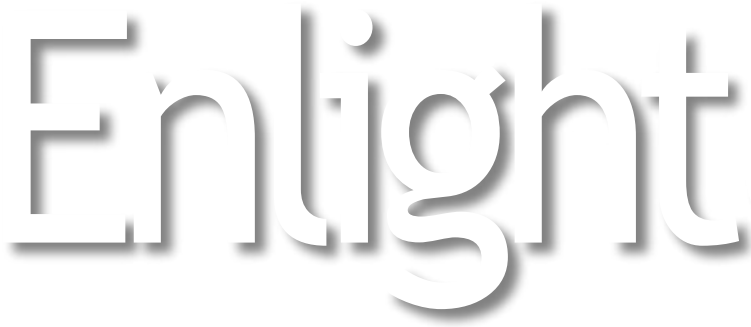

unexpected benefits - not the least of which is digital religious freedom.

Corporations are seeing the open source light. $Q$

\section{LOVE IT, HATE IT? LET US KNOW:}

queue-ed@acm.org or www.acmqueue.org/forums

PAUL FERRIS is a husband, father, and seasoned IT professional with more than 15 years of Unix and Linux

\section{Suggested Readings about Open Source Success \\ MySAP Business Suite on Linux \\ http://www.sap.com/linux/ \\ Oracle on Linux \\ http://www.oracle.com/ip/deploy/database/oracle9i/ index.html?oracle linux.htm}

How Amazon saved Amazon ("How Linux Saved Amazon Millions," Stephen Shankland, Margaret Kane, and

Robert Lemos, CNET, October 30, 2001.)

http://news.com.com/2100-1001-275155.htm

Google on Linux ("Google's Technical Highlights," 2003)

http://www.google.com/press/highlights.htm

Yahoo's open source infrastructure ("MySQL Powers Yahoo," Jeremy Zawodny, DM Review, 2003.)

http://www.dmreview.com/master.cfm?NavID=194\&EdID= 5421

eBay and other top online shopping sites are powered by Linux ("Linux Goes Shopping," Lisa DeCarlo, Forbes.com, October 8, 2003.)

http://www.forbes.com/2002/10/08/1008linux.htm

Linux provides competition for Microsoft ("Ballmer E-mail Urges Employees to Meet Linux Challenge," AP wire story, USA Today, June 5, 2003.)

http://www.usatoday.com/tech/news/2003-06-05-ballmeremail x.htm

Recent infrastructure market gains by Linux ("IDC Releases Server Numbers," Brian Proffitt, ServerWatch, March 3, 2003.)

\section{The Age of Corporate Open Source}

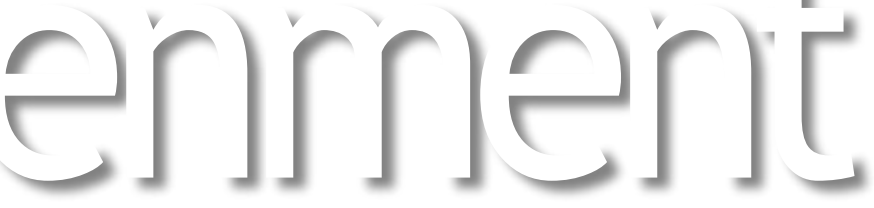

experience. He spent five years as a freelance writer on the open source front. Ferris has also developed and managed the software behind some of the most popular Linux Web sites. From 1999 to 2001, Ferris was an editor and developer for LinuxToday.com. His writings have appeared on Linuxjournal.com, Varlinux.org, ApacheToday.com, LinuxPlanet.com, and more. Ferris is currently a systems engineer at a Fortune $\mathbf{5 0 0}$ company. (c) 2003 ACM 1542-7730/03/0700 $\$ 5.00$.

\section{http://www.serverwatch.com/news/article.php/1975911}

Netcraft Web servers survey shows Apache's 60-plus percent market share of Web domain space ("Hosting Provider Performance Comparison Available," June 24, 2003.) http://www.netcraft.com/survey

\section{Suggested Reading on Microsoft Sales Tactics}

Bill Gates explains that current customers are Microsoft's top competitor ("Divided He Stands: Interview with Bill Gates," Leo Magno, Inquirer.net, June 19, 2000.) http://www.ing7.net/infotech/jun2000wk3/info main.htm

Analysis of internal strategies at Microsoft regarding Linux ("Halloween VII: Survey Says," OpenSource.org, November 5, 2002)

http://www.opensource.org/halloween/halloween7.php

Microsoft: Under no circumstances lose against Linux ("MS 'Slush' Fund Provides Big Discounts to Stop Linux-E-mail," by John Lettice, The Register, May 15, 2003.) http://www.theregister.com/content/4/30715.htm

Microsoft tries a discount tactic (and loses) the City of Munich, Germany ("Microsoft Loses City of Munich Deal to Linux," Hans Nagl, Forbes.com, May 28, 2003.) http://www.forbes.com/home europe/newswire/2003/05 28/rtr984204.htm

A leaked Microsoft memo indicates that previous antiopen source marketing attempts have failed ("Microsoft Memo: Linux Fight Backfiring," Scott Ard, CNET, November 6, 2002.) http://news.com.com/2100-1001964854.html?tag=bplst 